\title{
Outcome based Assessment using Fuzzy Logic
}

\author{
Abraham Varghese \\ Information Technology Department \\ Higher College of Technology \\ Muscat, Sultanate of Oman \\ Shajidmon Kolamban \\ Information Technology Department \\ Higher College of Technology \\ Muscat, Sultanate of Oman
}

\author{
Jagath Prasad Sreedhar \\ Information Technology Department \\ Higher College of Technology \\ Muscat, Sultanate of Oman
}

\author{
Sankara Nayaki \\ Information Technology Department \\ Adi Shankara Institute of Engineering and Technology \\ Cochin, India
}

\begin{abstract}
Outcome Based Education (OBE) or student centered learning is one of the key component in quality assurance and enhancement in the higher education. The OBE approach encourages students to become active learner rather than being passive as in the traditional teacher-centered learning approach. In OBE, teacher is a facilitator of the teaching learning process; therefore the quality of teaching learning process does not depends on how a Lecturer teaches the course, but on the skill or knowledge achieved by the students. The level of the attainment of Course Level Outcomes (CLOs) is the indicator of the skill, knowledge and behavior that students acquired at the end of the course. Therefore each and every activity conducted in the classroom has to be reflected in the assessment of course outcome, which is measurable. In this paper, an efficient way of assessing the course learning outcome using Fuzzy Logic is presented. The uniqueness of the method is it will give an accurate measure to assess the attainment level of the course by considering every parameter enabling the learning process.
\end{abstract}

Keywords-Outcome based Education; Course Learning Outcome; Fuzzy Logic

\section{INTRODUCTION}

The student centered learning motivates the students to become more responsible for their learning by involving themselves $100 \%$ in the teaching learning process. According to Heywood [1], "Education that is outcome-based is a learner-centered, results-oriented system founded on the belief that all individuals can learn". The key points in the Outcome Based Education (OBE) approach are [2,3]:

- Student learning outcome are clearly mentioned.

- The student's progress is evaluated based on demonstrated achievement.

- Multiple instructional and assessment strategies need to be available to meet the needs of each student.

- Assistance and adequate time need to be provided so that each student can reach the maximum potential.

Accordingly, the classroom activities are to be planned and facilitated based on the need and level of the students. CLOs give a clear picture on the knowledge and the skill achieved by the student at the end of the course. It does not depend on 'what the course Instructor (CI) teaches in the class', rather it depends on 'what knowledge students acquired and what they are able to do'. It focuses on the best way for individuals and organizations to get self-knowledge about where they are and what they want to be $[4,5]$. In short, Outcome based education (OBE) is a recurring education reform model where the learning philosophy focuses on empirically measuring student performance called outcomes.

Therefore, the continuous assessment to be made in systematic and accurate way such that the feedback obtained shall be an input for the teaching learning process to improve. In traditional way of grading system, the grading will be based on a cut of mark. The drawback of such grading is that it does not give accurate level of attainment in most of the cases. For example, a student gets 99 mark and another gets 90 mark will be graded as ' $\mathbf{A}$ ' even though the difference is 9 mark. At the same time a student gets 90 mark and another student gets 89 marks will be given different grade, where the difference is just only 1 mark. In order to reduce such discrepancy, fuzzy logic is introduced where degree of attainment is also incorporated along with the grade. In this paper, the focus is not to assign a grade, but assess the level of attainment of the learning outcomes based on fuzzy modelling approach. The remaining section is as follows. Section 2 gives the overview of the method. Section 3 gives the implementation details and results followed by the conclusion.

\section{METHODOLOGY}

A fuzzy set is a set containing elements that have varying degrees of membership in the set and it was introduced by Zadeh in 1965. This theory was proposed in terms of the membership function operating over the range [0-1] of real numbers. It is in contrast with classical or crisp set because members of a crisp set would not be members unless their membership is full or complete, in that set. If an element of universe, say $x$, is a member of fuzzy set, then the mapping is given by $\tilde{\mu}(x) \in[0,1][6],[7],[8]$.

Let $\tilde{A}$ be a fuzzy set defined on the universe $\mathrm{X}$ and $\tilde{B}$ be a fuzzy set defined on the universe Y. The Cartesian product between the fuzzy sets $\tilde{A}$ and $\tilde{B}$ indicates as $\tilde{A} \mathrm{x} \tilde{B}$ resulting in a fuzzy relation $\tilde{R}$ given by $\widetilde{R}=\tilde{A} \mathrm{x} \tilde{B} \subset \mathrm{X} \times \mathrm{Y}$ where $\tilde{R}$ has its 
membership function given by $\mu_{\mathrm{R}}(\mathrm{x}, \mathrm{y})=\mu_{\mathrm{AxB}}(\mathrm{x}, \mathrm{y})=\min (\mu \tilde{A}(\mathrm{x})$, $\mu \tilde{B}(\mathrm{x}))$. The Fuzzy inference system is used to convert crisp input to crisp output after doing fuzzification anddefuzzifcation. The: Fig. 1 shows the architecture of fuzzy inference system.

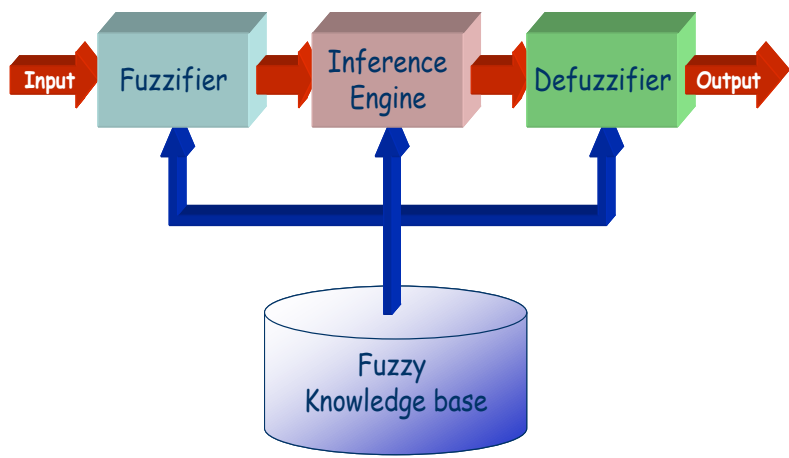

Fig. 1. The Architecture of Fuzzy Inference system

Fuzzifier converts the crisp input to a linguistic variable using the membership functions stored in the fuzzy knowledge base. Inference engine converts the fuzzy input to the fuzzy output using If-Then type fuzzy rules. Defuzzifier converts the fuzzy output of the inference engine to crisp using membership functions analogous to the ones used by the fuzzifier. The Commonly used fuzzy inference models are Mamdani Fuzzy models, Sugeno Fuzzy Models and sukamoto Fuzzy models $[9,10,11,12]$.In order to apply the fuzzy inference model, the subject 'calculus-1' for diploma course of Higher college of Technology, Muscat is chosen. The course outcome of this course is given in Table 1.

TABLE I. THE COURSE OUTCOME OF THE COURSE CALCULUS-1

\begin{tabular}{|c|c|}
\hline \multicolumn{2}{|c|}{ At the end of the course student will be able to: } \\
\hline CO1 & $\begin{array}{l}\text { Compute the existence of a limit, continuity and differentiability of } \\
\text { function at a point and its value, if exists. }\end{array}$ \\
\hline $\mathrm{CO} 2$ & $\begin{array}{l}\text { Determine the derivative of polynomial, trigonometric, exponential } \\
\text { logarithmic functions using standard techniques of differentiation. }\end{array}$ \\
\hline $\mathrm{CO} 3$ & $\begin{array}{l}\text { Solve tangent problem, rate of change, extreme value, } \\
\text { increasing/decreasing interval and concavity using derivative. }\end{array}$ \\
\hline $\mathrm{CO} 4$ & Verify Mean Value theorem and Rolle's Theorem \\
\hline $\mathrm{CO5}$ & $\begin{array}{l}\text { Evaluate indefinite and indefinite integrals of functions using standa } \\
\text { integration techniques }\end{array}$ \\
\hline $\mathrm{CO6}$ & Find area between two curves using definite integrals \\
\hline
\end{tabular}

At the end of the semester, each CLOs has to be assessed and the feedback to be given to the succeeding semester for improvement. The evaluation to be done based on the number of students acquired a specified target. Table 2 gives the suggested plan for the continuous assessments.
TABLE II. CONTINUOUS ASSESSMENT PLAN

\begin{tabular}{|c|c|c|}
\hline & $\begin{array}{c}\text { Continuous } \\
\text { Formative-Summative Assessments }\end{array}$ & $\begin{array}{c}\text { Marks } \\
\text { (100) }\end{array}$ \\
\hline \multirow{4}{*}{ Exam } & Quiz-1 & 7 \\
\hline & Quiz-2 & 8 \\
\hline & Midterm & 25 \\
\hline & Final Exam & 50 \\
\hline \multirow{5}{*}{$\begin{array}{l}\text { Class room } \\
\text { Activity }\end{array}$} & One minute paper & \multirow{5}{*}{10} \\
\hline & Muddiest Point Activity & \\
\hline & Think Pair Share Method & \\
\hline & Concept Mapping & \\
\hline & Assignment & \\
\hline
\end{tabular}

The details of the classroom activity are as follows:

Muddiest Point Activity: Muddiest Point" exercises are active learning techniques typically conducted at the end of a topic, chapter or class period. In a "Muddiest Point" exercise, students are anonymously asked to report what idea, topic, etc. about the previous lesson was confusing or unclear. Faculty members collect all "Muddiest Point" responses and later read and analyze them to see what areas of the lesson students are unclear about. Here are some ways to do that: a) Start off the next lecture by clarifying confusing topics b) Provide simple explanations, etc. on a course website.

One Minute Papers: At the end of a topic or module, students can be instructed to note down the most important/significant concept from a certain lesson, and list their major questions related to a lesson/lecture/chapter. One Minute papers can be debriefed by providing written feedback on students minute papers, writing frequently listed major points on the board, discussing answers to students questions with the class.

Think - Share Pair Method: After 10 or 15 minutes lecture, faculty members pose a question to the class and then allow a couple of minutes for each individual student to think and discuss with the student next to him. Finally, the faculty member will ask one or two random pairs to share their response with the class.

Concept mapping: Concept mapping is a technique that helps the students to organize the lecture and/or recognize the relationships between ideas by creating a visual map of the map of the connections.

\section{Question Paper:}

In order to maintain the quality and ensue the coverage of COs, the question paper is prepared in such a way that each question tests understanding/ analysis / application level of the student's knowledge. Each question maps to one or more course out comes. The sample format of the question bank is given in Table 3. 
TABLE III. THE COGNITIVE LEVEL OF QUESTION PAPER

\begin{tabular}{|l|l|l|}
\hline Questions & $\begin{array}{l}\text { Cognitive Level } \\
\text { (knowledge/ } \\
\text { understanding/ } \\
\text { analysis \& } \\
\text { applications) }\end{array}$ & CLO \\
\hline Chapter 1 & Application & CO2 \\
$\begin{array}{l}\text { 1) If } \mathrm{f}(x)=\cos (\pi x), g(x) \pi=\frac{1}{x+3}, \\
\text { find }(f o g)^{\prime} \text { at } \mathrm{x}=-2 \text {. Compare it with } \\
(g \circ f)^{\prime}\end{array}$ & CO3 \\
$\begin{array}{l}\text { 2) Find the equation of the tangent line } \\
\text { to the curve given by the parametric } \\
\text { equations } x=2 t^{2}-1, y=2 \operatorname{sint} \text { at } \\
t=\pi ? \text { Also find } \frac{d^{2} y}{d x^{2}} \text { at } t=\pi\end{array}$ & Analysis & CO1 \\
\hline $\begin{array}{l}\text { 3.Find the limit of the function } f(x)= \\
\frac{1-\sqrt{x+1}}{x} \text { as } x \rightarrow 0\end{array}$ & understand & \\
\hline
\end{tabular}

\section{IMPLEMENTATION}

The marks/grade obtained for each course outcome is recorded. The attainment of the course outcome is assessed through internal examinations and graded class activities. The target of the internal examinations is decided by the coordinator of the subject. At the middle of the semester the course level outcome attainment can be reviewed and appropriate action can be taken. The course outcome can be evaluated as follows:

\begin{tabular}{|l|l|}
\hline Number of students & Mark obtained \\
\hline $\mathrm{C}_{1}$ & $>=90 \%$ \\
\hline $\mathrm{C}_{2}$ & $>=80 \% \&<90 \%$ \\
\hline $\mathrm{C}_{3}$ & $>=70 \% \&<80 \%$ \\
\hline $\mathrm{C}_{4}$ & $>=60 \% \&<70 \%$ \\
\hline $\mathrm{C}_{5}$ & $>=50 \% \&<60 \%$ \\
\hline The Course outcome Score $=\frac{5 \times C_{1}+4 \times C_{2}+3 \times C_{3}+2 \times C_{4}+C_{5}}{N \times 5} \times t$ \\
\hline
\end{tabular}

Each course gets a value in the range $[0, \mathrm{t}]$ based on the mark obtained in Quiz, Assignment, midterm, Final Exam and other classroom Activities. It is graded as slightly, moderately and substantially using Fuzzy membership functions. The student learning outcome can be very well modelled using Fuzzy membership functions and fuzzy rule. The use of fuzzy is suitable to model vagueness in assessing the student learning outcomes. For Example, out of the 6 CLOs, if 3 CLOs score are 'slightly' attained (in the range 0 to 1.5), 2 COs are 'Moderately' attained (between 1 to 2), and $1 \mathrm{CO}$ score is 'substantially' attained (1.5 to 3), then how to rate the performance of the course? The fuzzy reference engine can model it in a very efficient way. The input to the fuzzy reference engine here is course outcomes score and the output is the level of attainment such as 'Poor', 'Satisfactory', 'Good', 'Very Good', 'Excellent'. The Fig. 2 shows the block diagram of the fuzzy model.

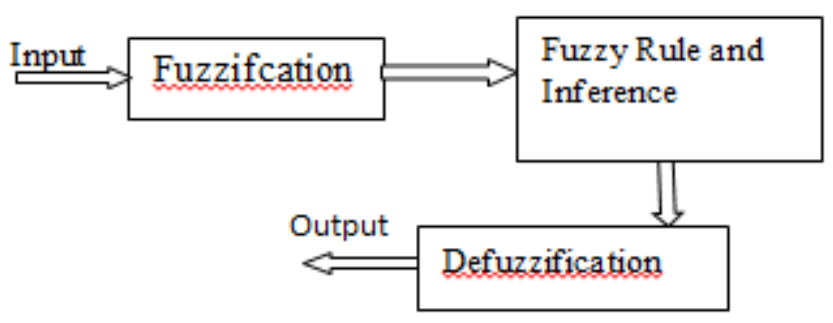

Fig. 2. Block diagram of the fuzzy model

\section{A. Fuzzification of input and output spaces}

The fuzzification of the input space are done using 3 fuzzy linguistic variables 'Slightly', 'Moderately' and 'Substantially'. Similarly, the output is graded as 'poor', 'Satisfactory','Good', 'Very good', and Excellent. The fuzzy definition of the linguistic variable is given in the Table $4 \& 5$.

TABLE IV. FUZZIFICATION OF INPUT VARIABLE

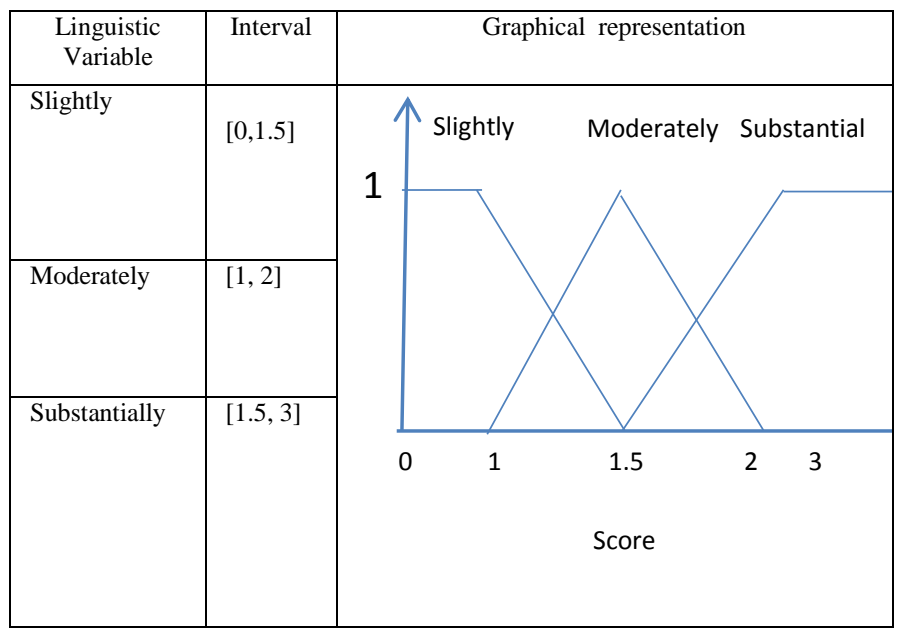

TABLE V. FUZZIFICATION OF OUTPUT VARIABLE

\begin{tabular}{|c|c|c|}
\hline $\begin{array}{c}\text { Linguistic } \\
\text { Variable }\end{array}$ & Interval & Equations \\
\hline Poor & {$[0,1.5]$} & $\left\{\begin{array}{cc}1, & x \leq 1 \\
1.5-x, & 1 \leq x \leq 1.5\end{array}\right\}$ \\
\hline Satisfactory & {$[1,2]$} & $\left\{\begin{array}{ll}x-1, & 1 \leq x \leq 1.5 \\
2-x, & 1.5 \leq x<2\end{array}\right\}$ \\
\hline Good & {$[1.5,2.5]$} & $\left\{\begin{array}{ll}x-1.5, & 1.5 \leq x \leq 2 \\
2.5-x, & 2 \leq x<2.5\end{array}\right\}$ \\
& $\left\{\begin{array}{rr}x-2, & 2 \leq x \leq 2.5 \\
1, & x \geq 2.5\end{array}\right\}$ \\
\hline Excellent & {$[2.5,3]$} & \\
\hline
\end{tabular}

\section{B. Generation of fuzzy rules}

Fuzzy rules are very essential part in the fuzzy modeling, which maps the input and output spaces. The following are some fuzzy rules generated to map 5 input and 5 outcomes. 


\begin{tabular}{|c|c|c|c|c|c|c|}
\hline SN NO & $\mathrm{CO} 1$ & $\mathrm{CO} 2$ & $\mathrm{CO}$ & $\mathrm{CO} 4$ & $\mathrm{CO}$ & OUTPUT \\
\hline 1 & $\mathrm{~S}$ & $\mathrm{~S}$ & $\mathrm{~S}$ & $\mathrm{~S}$ & $\mathrm{~S}$ & POOR \\
\hline 2 & $\mathrm{~S}$ & $\mathrm{~S}$ & $\mathrm{~S}$ & $\mathrm{~S}$ & $\mathrm{M}$ & POOR \\
\hline 3 & $\mathrm{~S}$ & $\mathrm{~S}$ & $\mathrm{~S}$ & $\mathrm{M}$ & $\mathrm{M}$ & POOR \\
\hline 4 & $\mathrm{~S}$ & $\mathrm{~S}$ & $\mathrm{~S}$ & $\mathrm{~S}$ & $\mathrm{SU}$ & POOR \\
\hline 5 & $\mathrm{~S}$ & $\mathrm{~S}$ & $\mathrm{~S}$ & $\mathrm{SU}$ & $\mathrm{SU}$ & SATISFACORY \\
\hline 6 & $\mathrm{~S}$ & $\mathrm{~S}$ & $\mathrm{~S}$ & $\mathrm{M}$ & $\mathrm{SU}$ & SATISFACTORY \\
\hline 7 & $\mathrm{~S}$ & $\mathrm{~S}$ & $\mathrm{M}$ & $\mathrm{M}$ & $\mathrm{M}$ & SATISFACTORY \\
\hline 8 & $\mathrm{~S}$ & $\mathrm{~S}$ & $\mathrm{M}$ & $\mathrm{M}$ & $\mathrm{SU}$ & SATISFACTORY \\
\hline 9 & $\mathrm{~S}$ & $\mathrm{M}$ & $\mathrm{M}$ & $\mathrm{M}$ & $\mathrm{M}$ & SATISFACTORY \\
\hline 10 & $\mathrm{~S}$ & $\mathrm{SU}$ & $\mathrm{SU}$ & $\mathrm{SU}$ & $\mathrm{SU}$ & GOOD \\
\hline 11 & $\mathrm{~S}$ & $\mathrm{~S}$ & $\mathrm{SU}$ & $\mathrm{SU}$ & $\mathrm{M}$ & GOOD \\
\hline 12 & $\mathrm{~S}$ & $\mathrm{SU}$ & $\mathrm{SU}$ & $\mathrm{SU}$ & $\mathrm{M}$ & GOOD \\
\hline 13 & $\mathrm{~S}$ & $\mathrm{M}$ & $\mathrm{M}$ & $\mathrm{M}$ & $\mathrm{SU}$ & GOOD \\
\hline 14 & $\mathrm{M}$ & $\mathrm{M}$ & $\mathrm{M}$ & $\mathrm{M}$ & $\mathrm{M}$ & GOOD \\
\hline 15 & $\mathrm{SU}$ & $\mathrm{SU}$ & $\mathrm{SU}$ & $\mathrm{SU}$ & $\mathrm{M}$ & EXCELLENT \\
\hline 16 & $\mathrm{SU}$ & $\mathrm{SU}$ & $\mathrm{SU}$ & $\mathrm{SU}$ & $\mathrm{SU}$ & EXCELLENT \\
\hline
\end{tabular}

The method has been implemented using Mamdani Fuzzy inference system in Matlab R2016a. The defuzzification is performed using centroid method and composition of the input are done using max-min method. It has been evaluated on 5 sections of calculus class and the observation is summarized in Table 6.

TABLE VI. COURSE OUtCOME SCORE OF 5 SECTIONS

\begin{tabular}{|l|l|l|l|l|l|l|l|}
\hline $\begin{array}{l}\text { Secti } \\
\text { on }\end{array}$ & $\mathrm{CO} 1$ & $\mathrm{CO} 2$ & $\mathrm{CO} 3$ & $\mathrm{CO} 4$ & $\mathrm{CO} 5$ & $\begin{array}{l}\text { OUTPUT } \\
\text { SCORE }\end{array}$ & REMARKS \\
\hline $\mathrm{A}$ & 1.28 & 1.25 & 1.09 & 1.36 & 1.31 & 0.97 & Poor \\
\hline $\mathrm{B}$ & 1.02 & 0.97 & 1.64 & 1.55 & 1.74 & 1.58 & Satisfactory \\
\hline $\mathrm{C}$ & 1.64 & 1.45 & 1.32 & 1.55 & 1.7 & 2 & Good \\
\hline $\mathrm{D}$ & 2.1 & 2.3 & 1.7 & 2.3 & 2.5 & 2.56 & Excellent \\
\hline $\mathrm{E}$ & 1.9 & 2.3 & 1.7 & 2.46 & 0.8 & 1.5 & Satisfactory \\
\hline
\end{tabular}

It is observed that output score can be obtained for any continuous data between 0 and 3 . This means that every activity conducted in the class room will be directly reflected in the output score and thus this output score gives the correct indication of the skill and knowledge achieved by the students. The performance of the any section can be assessed by setting a target on the output score.

For Example,

Level 1- output score is above 2.5 (CLO substantially achieved)

Level 2- output score is between 2 and 2.5 ( CLO Moderately achieved)

Level 3- output score is between 1.5 and 2 ( CLO slightly achieved).

If the score is below 1.5, CLO is not achieved and remedial action to be done in the next semester. Those who achieved Level 1 can try for achieving Level 2 and so on. One sample output is shown in Fig 3.

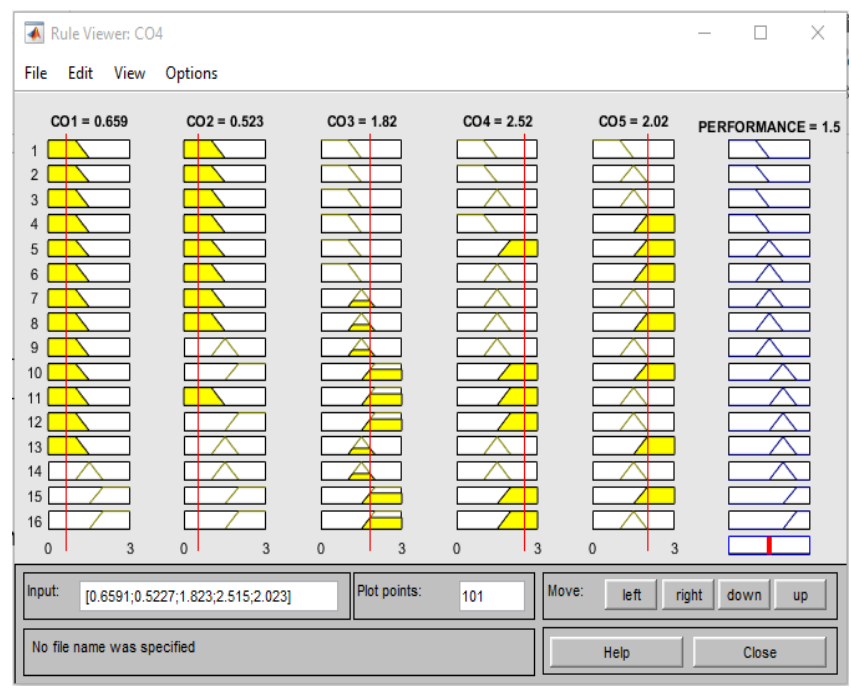

Fig. 3. The output score corresponds to the input $[0.65,0.52,1.82,2.51$, 2.023] using Mamdani model

\section{CONCLUSION}

This paper describes how fuzzy Logic can be used to assess continuous performance of the any course based on the course learning outcome of that course systematically. The importance of the method is that it takes care of every minute parameter enabling teaching learning process in order to assess the performance of the system. Accordingly, remedial action can be suggested for the active involvement of the students in the teaching learning process, and thus quality education is enhanced.

\section{REFERENCES}

[1] Heywood,Assessment in Higher Education, 2nd ed. New York:Wiley, 1989.

[2] Adedoyin O. O., Shangodoyin D. K. (2010) 'Concepts and practices of outcome based education for effective educational system in Botswana', European Journal of Social Sciences, 1392, 161-70F. Marton, D. J. Hounsell, and N. J. Entwistle, Eds. Edinburgh, U.K.:Scottish Academic, 1984, pp. 1-18.

[3] Y. W. Leung, "Least-square-error estimate of individual contribution ingroup project,"'IEEE Trans. Educ., vol. 41, pp. 282-285, Nov. 1998.

[4] Fedler R. M., Brent R. (2003) 'Designing and teaching courses to satisfy the ABET engineering criteria', Journal of Engineering Education, 92 (1), 7-25

[5] Gladie L., Connie S. (2010) 'Using an outcome-based education approach to facilitate student learning in financial accounting in Hong Kong', Proceedings of ASBBS Confrence, Las Vegas, 17 (1), 944-9

[6] Zadeh, L.A. Fuzzy sets. Inf. Control 1965, 8, 338-353.

[7] Feng and L. D. Xu, (1999)“Decision support for fuzzy comprehensive evaluation of urban development," Fuzzy Sets Syst. , vol. 105, pp. 112.

[8] G. J. Klirm and B. Yuan, (1995) Fuzzy Sets and Fuzzy Logic: Theory and Applications. Englewood Cliffs, NJ: Prentice-Hall.

[9] J. R. Echauz and G. J. Vachtsevanos, (1995) "Fuzzy grading system," IEEE Trans. Educ., vol. 38, no. 2, pp. 158-164,.

[10] Fourali, C. (1997). Using fuzzy logic in educational measurement: The case of portfolio assessment. Journal of evaluation and research in education, 11(3). 129-148.

[11] Molyneaux, T. Setunge, S. Gravina, R. and Xie, M. (2006). An evaluation of the learning of structural engineering concepts during the first two years of a project-based engineering degree, European Journal of Engineering Education, 32 (1), 1-8. 